\title{
Importance of process simulation in the initiative phases of mould part construction
}

\author{
MALCOVSKÝ Miroslav ${ }^{1}$, BALOG Michal $^{2}$, JURKO Jozef ${ }^{3}$ \\ (miroslav.malcovsky@tuke.sk ${ }^{1}$, michal.balog@tuke.sk²,jozef.jurko@tuke.sk ${ }^{3}$ )
}

Faculty of manufacturing technologies with a seat in Prešov

The Technical University of Košice, Bayerová 1, Prešov

\begin{abstract}
The publication points out at the importance of the simulation in the initiative preparations of the mould part and the form for mould injection of the plastic material in construction design. It highlights the precise material choice and calls attention to defect prevention, which is needed already in the initiation of the individual mould parts construction models and in the correct cooling design of the plastic mould injection, as to ensure balanced mould part cooling and to prevent later deformation and increase in price, as well as to shorten the construction time.
\end{abstract}

Key words: simulation, process, deformation, mould injection, mould part

\section{Introduction}

The design, development and the construction themselves are difficult processes, which based on the construction worker and the technology expert lead to achieving optimal and effective results of the construction process. The simulations for easier and improved construction are important already in the initiative phases of the component design, in this case of the mould part constructed by plastic mould injection into a form. It starts with an idea, similar to any other project, and comes up to an expedition and a profit. What if the mould part does not correspond with the qualities expected? It is needed to remove all the defects, which can be prevented with a simulation.

Technological process and its result in the machinery industry is in some situations very much predictable in today's world. In the plastic mould injection process, a computer simulation is used and it can predict the defects in use of the given material and its behaviour already in the initiative phases of the form design. The primary role of each machinery construction company is to ensure a construction process of high quality. Keeping track of all the initial parameters entering the construction process from the beginning makes improvement and achieving high-quality results in the construction process much easier.

\section{Mould part construction design:}

The mould part development and adjustment comes from the constructer's experiences. If the constructer feels like the mould part could be deformed compared to the designed geometry, it is needed to enlarge the ribbing or even make the walls heavier, so that there will not be a bending on the opposite site of the intake - at the place where the material is being pushed into. According to the given mould part construction, the form constructer could adjust the form only by cooling or changing the intake placement. The intake placement is done during the development construction of the mould part. The placement and the enlargement of the intake make compression bigger. There are many options how to straighten the mould part and how to prevent the 
deformation. During the simulation, the constructer tries different scenarios, he changes the size and the number of the ribs, fills in the circumference, strengthens the bottom parts of the mould part, lightens the thin parts where there would flow more material, or there can be made a hole instead of the thick post where a screw would be inserted [1]
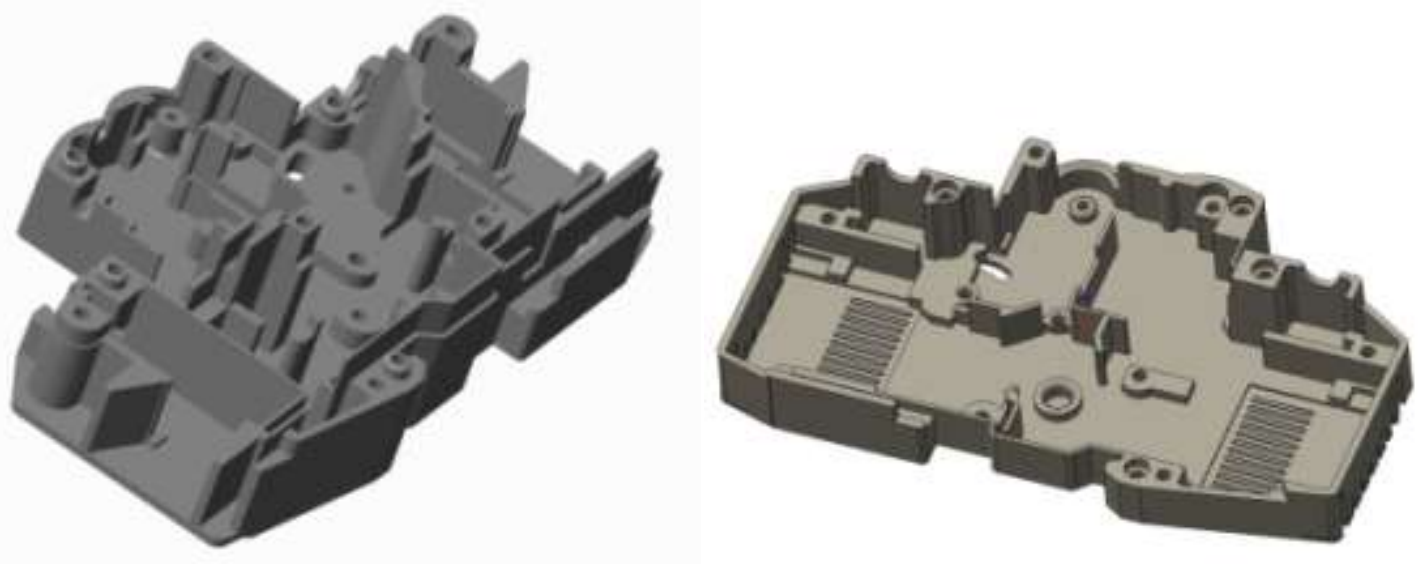

Fig. 1. Mould part construction design.

During the simulation of material flow, when the orientation of glass fibres changes from vertical flow into horizontal, the deformation of the mould part can be predicted according to the change in the flow direction. Thanks to the simulations of the material compression and the air bubbles creation, where the compressed air would over-heat, the form ventilation can be designed, so that the compressed air is ventilated from the form and the diesel effect would be prevented. Standard bending often occurs on several components. It can be disposed by adding a second intake or changing its position, so that its orientation would be identical with the flow orientation of the melt. Given modification can straighten the component. Parts with thick walls usually produce deformations due to material dragging and build-up. The simulation should be performed before the form to avoid possible problems that would not be possible to dispose of. It is all about the mould part development and construction while trying different ribs placement variations and other construction elements in different positions. The simulation can be also used to relieve the cycle when changing the input parameters.

\subsection{Deformation simulations:}

Many factors depend on the characteristics of the chosen material. During the simulation, material PA66 was used. Extruded material PA66 is known for higher thickness abrasion-resistance, compared to the basic PA6. Its mechanical characteristics are very similar to the material PA6G; however the PA66 has higher perseverance and higher cost of acquisition. [6] 
Characteristics comparison with other materials:

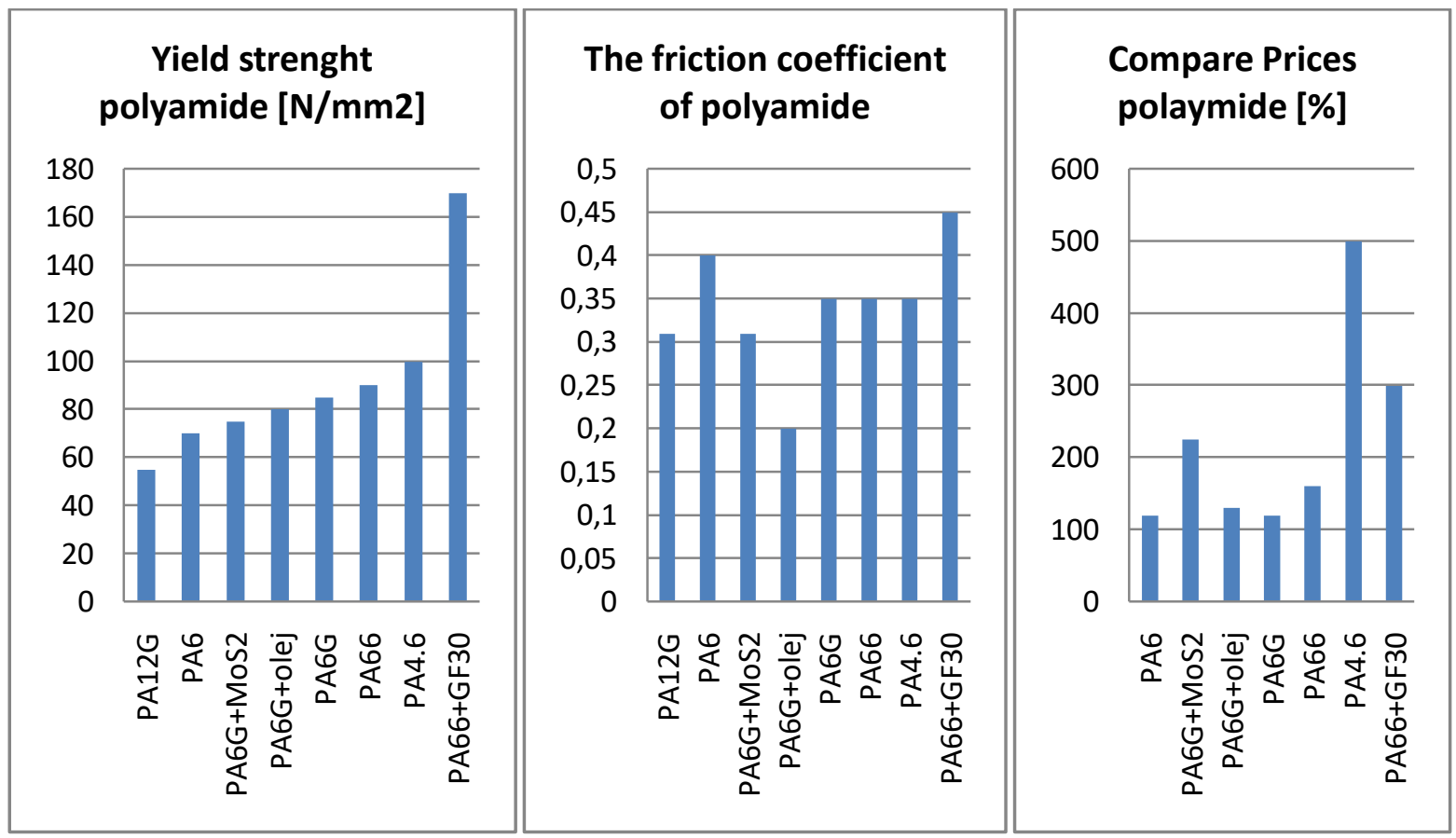

Fig. 2. Comparison materials PA6.6[7]

Deformation analysis could theoretically point out how much the mould part deforms or bends, which can be eliminated by cooling improvement, for example. This analysis shows how of many hundredths or tenths of millimetre is the virtual value higher or lower than the real value. The simulation would show the bending but it cannot give the $100 \%$ accurate difference [2].

\subsection{Construction design of the form:}

After the mould part simulation and the results analysis, it is appropriate to make also the cooling simulation with the construction design of the form. Different cooling canals average should be tried. The most important is to ensure even cooling on the whole circumference of the mould part [4].
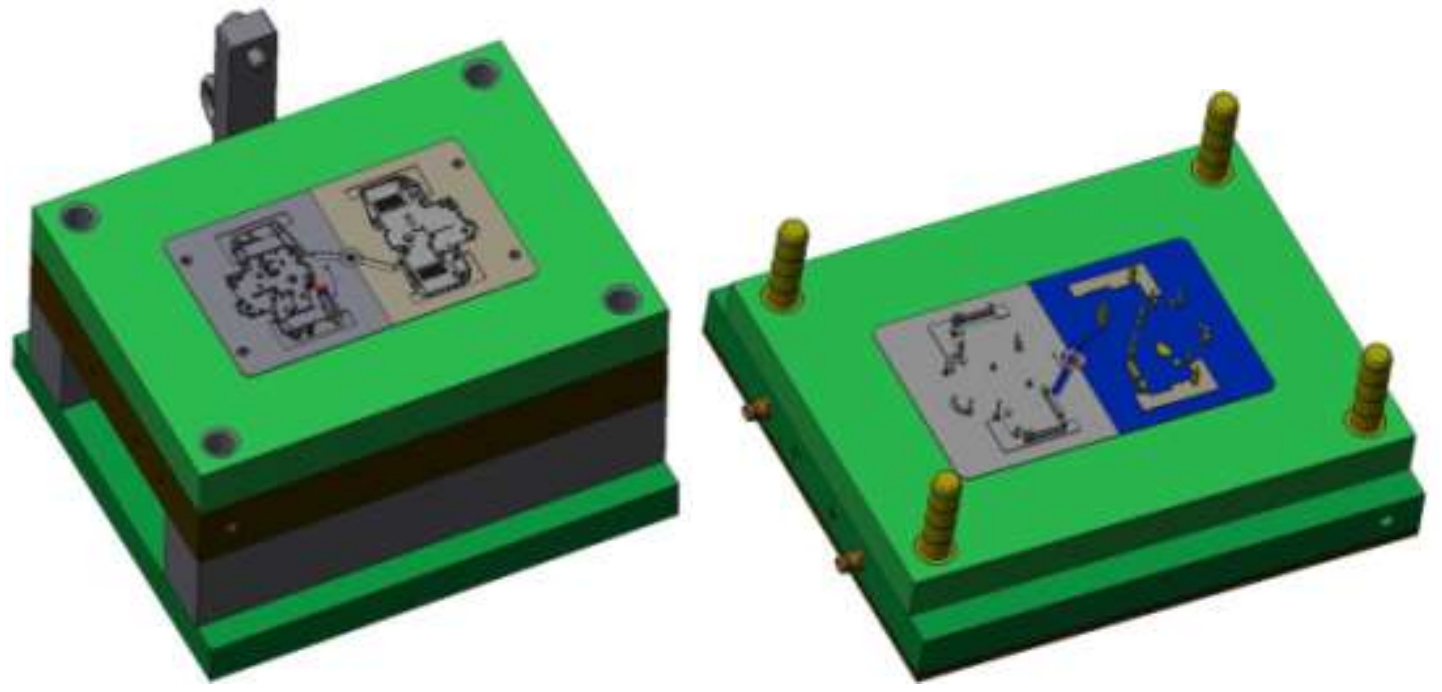

Fig. 3. Construction design of the form. 
From the point of the deformation, if we do not know the simulation and it would show $0.5 \mathrm{~mm}$ while we measure $0.3 \mathrm{~mm}$, the form is designed correctly. To choose bigger or lesser evil when deciding from which point to bend the deformation could be appropriate. So called "opposite bending" to straighten the mould part is created.

\section{Flow simulation:}
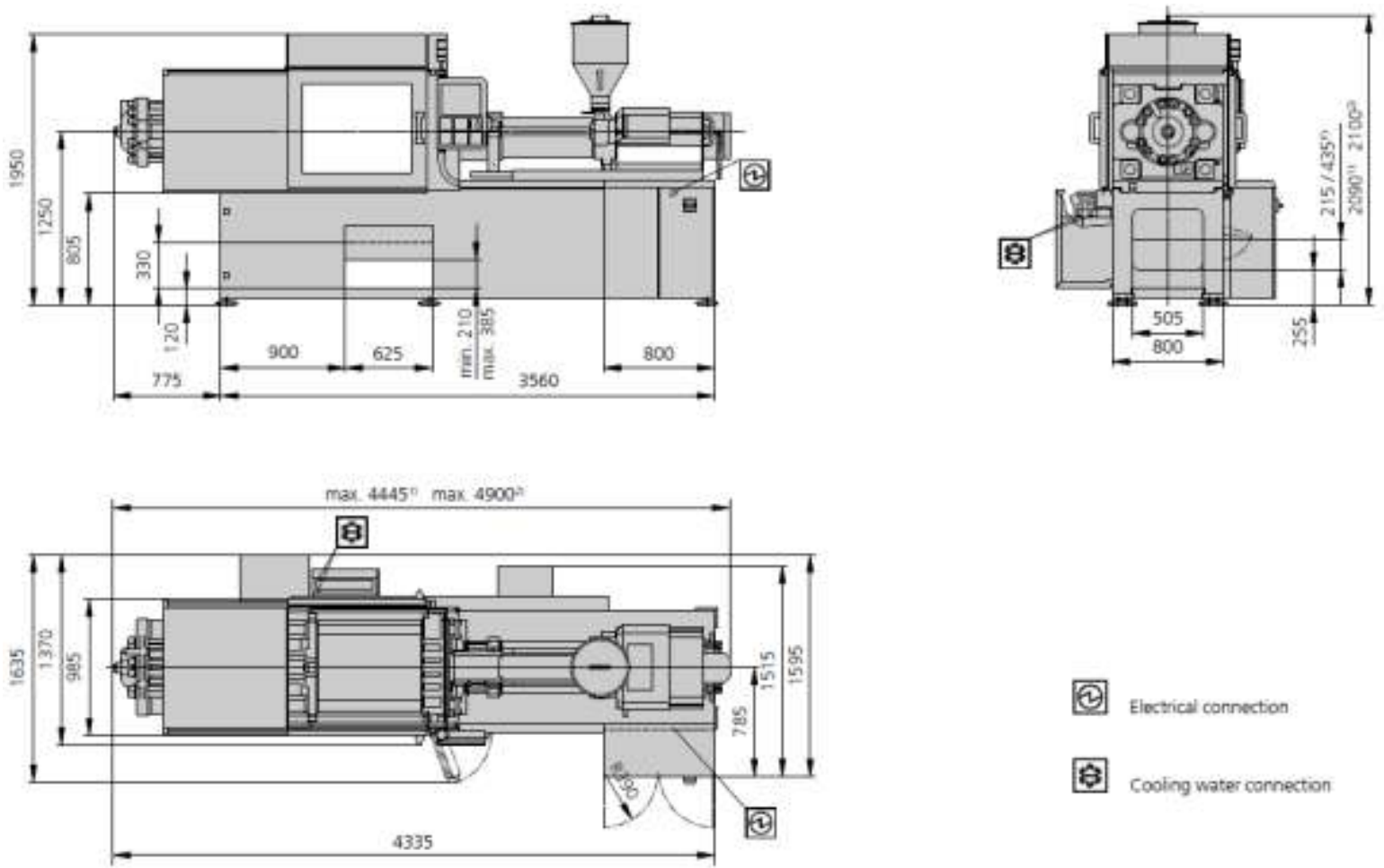

Electrical connection

图

Cooling water connection

Fig. 4. Injection molding machine ARBURG.

The flow simulation offers a complete report in the form of videos and individual parts can show the advancing of the flow and thus the individual intakes or construction parts of the form can be changed to get precise results $[5]$.

During the moldflow simulation, the original conditions as on the ARBURG injection molding machine were created [6].

Table 1.Injection molding possibilities.

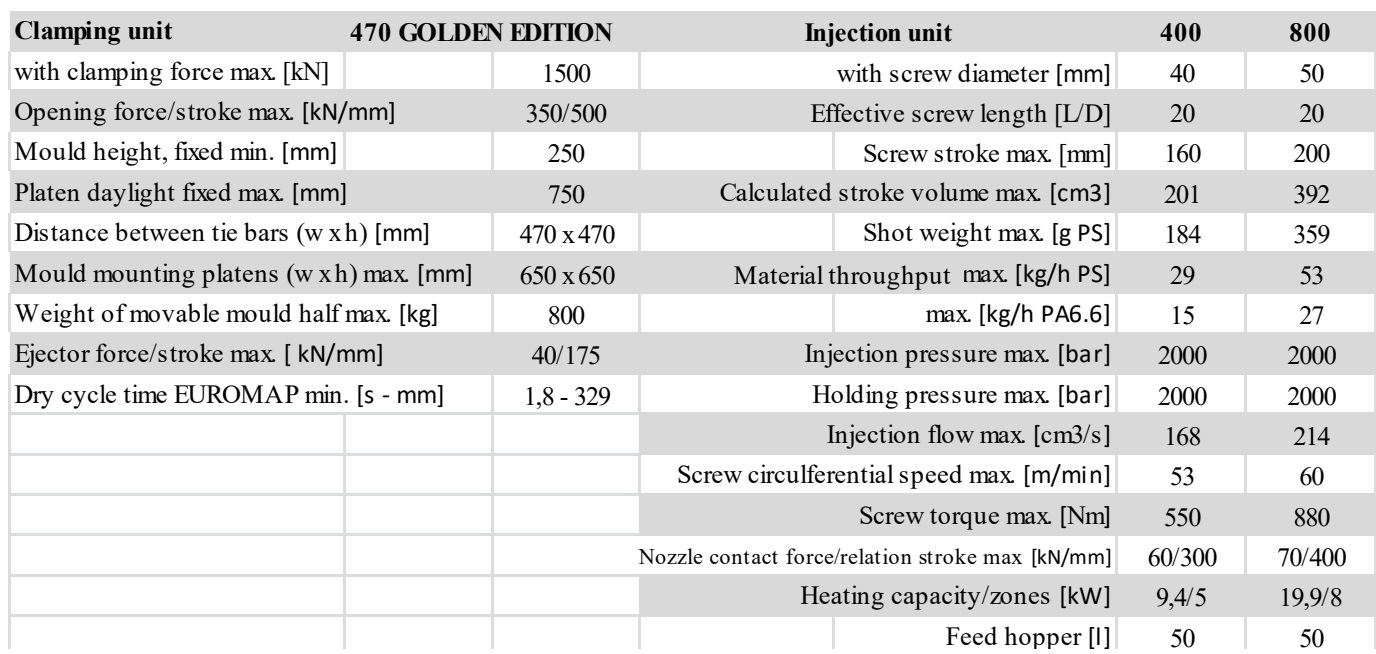




\subsection{Preasurre drop}

When the hollow is filled with the melt and compressed, the melt coagulates and diminishes in volume. The volume loss created needs to be refunded with inserting additional, small amount of the melt into the form. Pressure drop is one of the constants that greatly affect the inside case of injection, i.e. the structure of the product. The pressure drop amount and its duration need to be in accord with the melt cooling and its thickening. Pressure drop equals $40-60 \%$ of the mould injection pressure. The pressure drop is turned on when the form is filled for $95-98 \%$. In the initial phase, right after the material compression, the pressure drop should be higher so that the form is filled with the additional small amount of material quickly, while the melt is still in liquid state. However, at the end the pressure drop needs to be lowered, which can be seen in the image with the colour scale. [6]

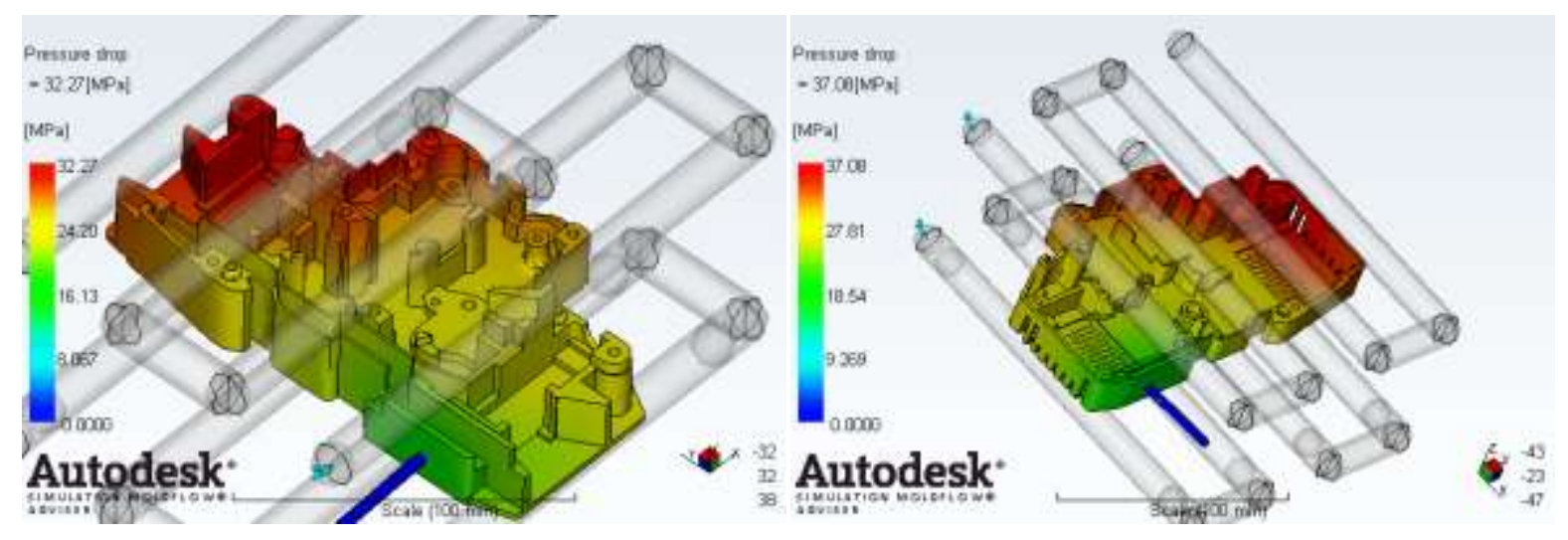

Fig. 5. Preasurre drop.

Table 2. Injection conditions.

\begin{tabular}{|l|l|}
\hline Injection preassure & $110 \mathrm{MPa}$ \\
\hline Injection time & $1.2 \mathrm{~s}$ \\
\hline Melt tepmerature & $290{ }^{\circ} \mathrm{C}$ \\
\hline Preassure drop & $75 \mathrm{MPa}$ \\
\hline Preassure drop time & $2,15 \mathrm{~s}$ \\
\hline Cooling time & $25 \mathrm{~s}$ \\
\hline Mold temperature & $80^{\circ} \mathrm{C}$ \\
\hline Medium temperature & $80^{\circ} \mathrm{C}$ \\
\hline
\end{tabular}

\subsection{Weld lines}

Weld lines are created when two flows join together, when the flows from two intake mouths join, or when the thick and the thin parts of the component cause division and following joint of the flows in the form hollow, which is caused by the unequal geometry. It can look like an unnoticeable weld joint, a crease with rounded sides or, in the worst case, as a crack. Weld line is not only a visual mistake, but with the transparent plastics also an optical one. It can also weaken the component solidity for 10-20\%, depending on its positioning. From the technological point of view, the solidity of weld line is depends on the type of the plastic, the temperature of the melt and the speed of the mould injection. On the analysed product, weld lines were found on the place of flows joints which was, however, not considerable. 


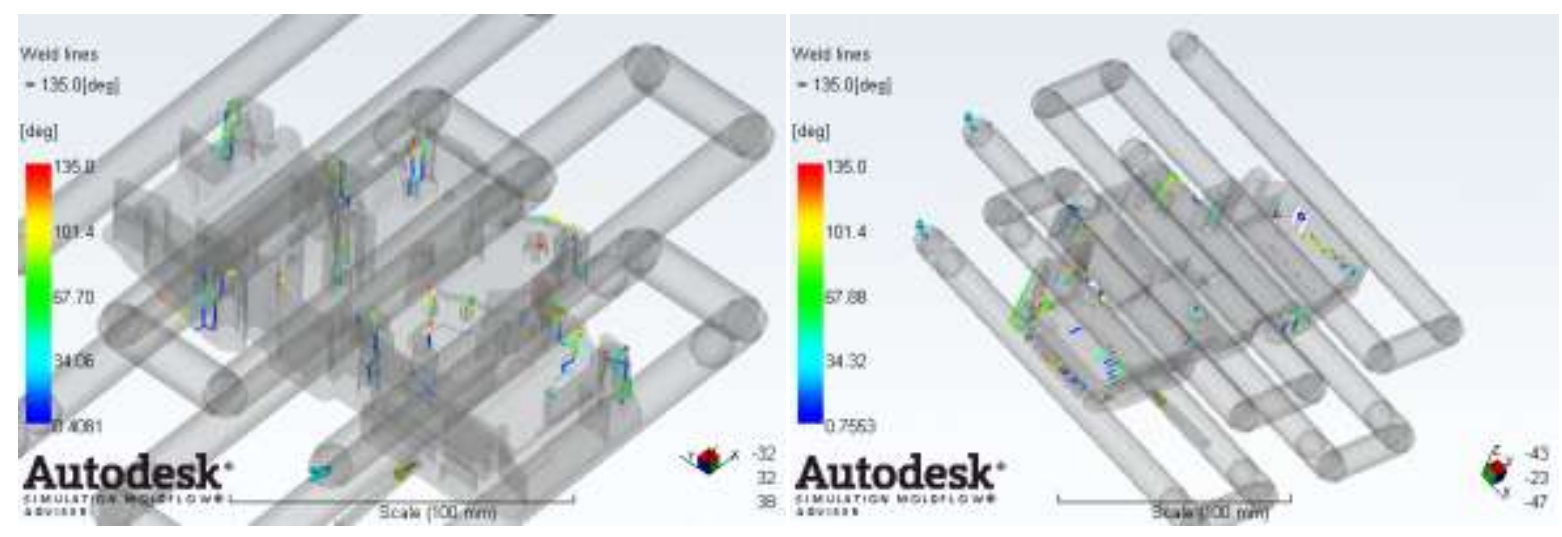

Fig. 6. Weld lines.

\subsection{Temperature at flow front}

The melt flow orientation shows the way in which the melted material flows in the form hollow and whether this orientation is correct. The material flows from the intake mouth through the hollow to the other end, where the two flows join together. It is also visible on the time simulation. If the material does not have right flow orientation, the products could be unfinished. The orientation depends on the injection pressure and the speed, as well as the temperature of the melted material. [8]

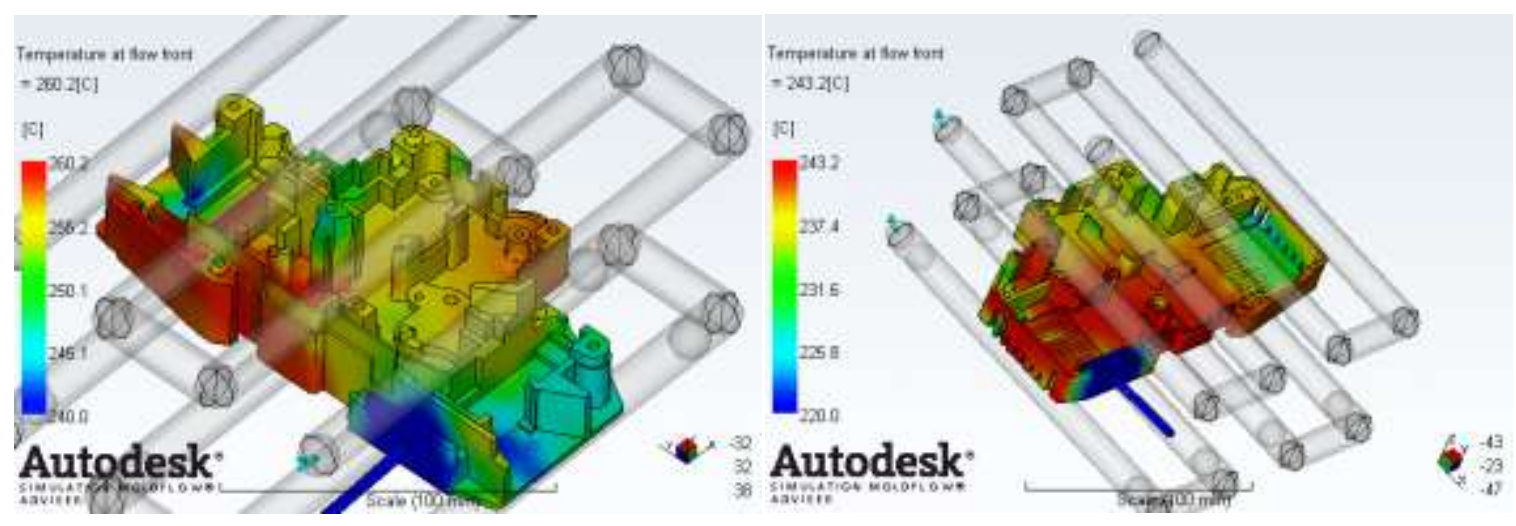

Fig. 7. Temperature at the flow front.

The dimension of the inlet system and the cooling system are important for simulation [6]:

With the multiple forms, an appropriate gradation of the inflow canals needs to be kept. The precise diameter of the inflow can be insured only with the computer simulation analysis. However, in the real practice, in most of the cases this is possible with the experience and the basic theoretical knowledge. [3]

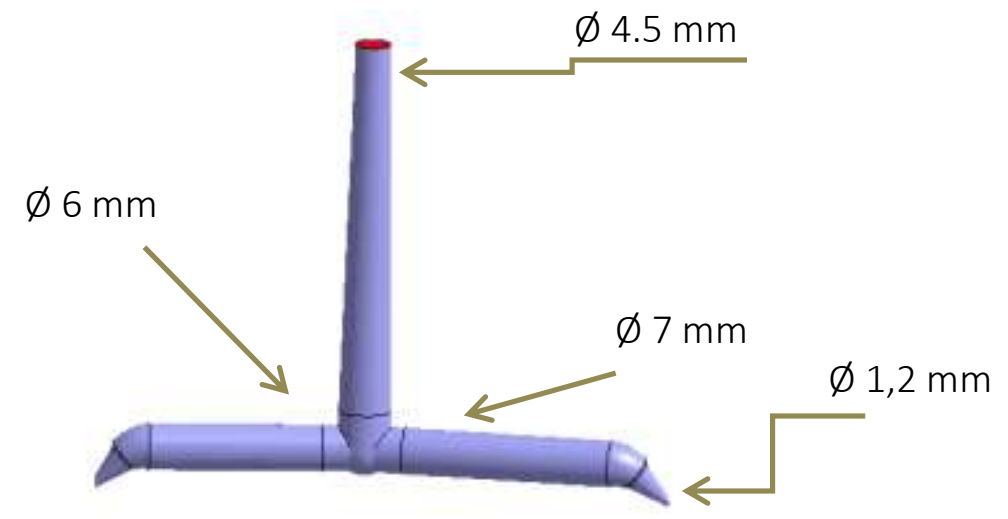

Fig. 8. Inlet system. 
The canals should be as short as possible, ideally of the same length for all the form's cavities so that identical pressure conditions are created, which is needed to be followed especially when in production of mould parts identical in size.

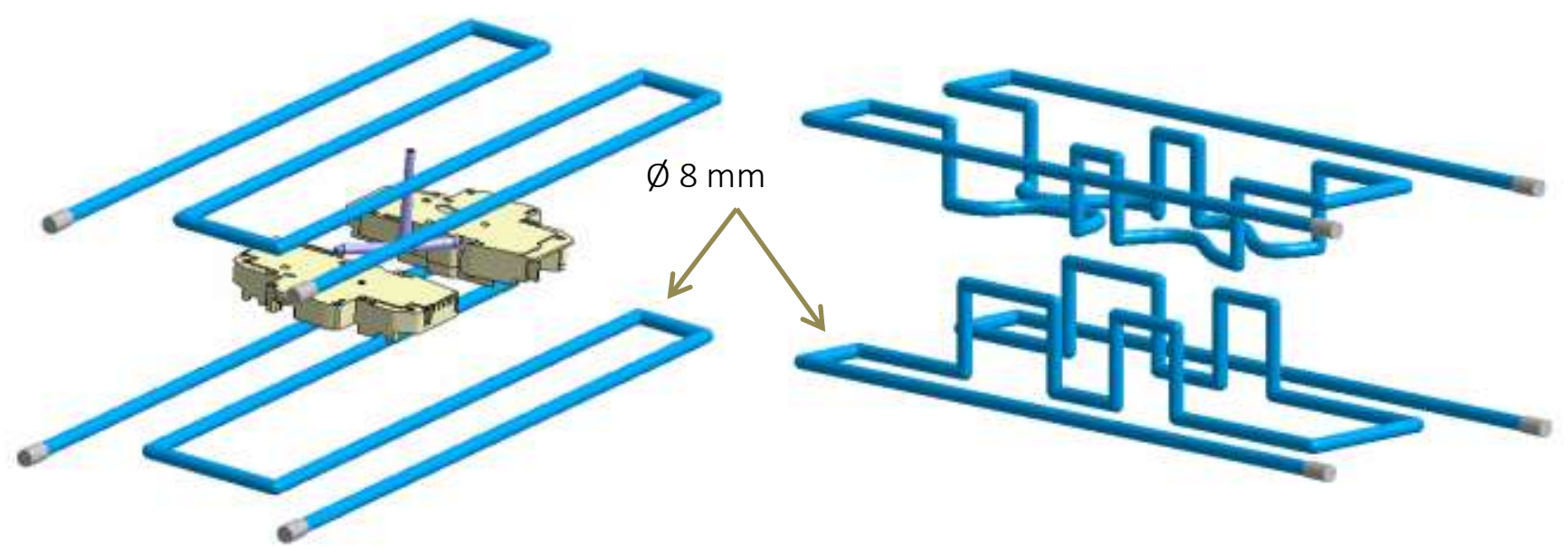

Fig. 9. Cooling system.

The organisation and dimensioning of the cooling system inside of the form is very influential on the injection characteristics, it's deformation and on reaching the cooling time and placing the form into the cycle. With the current state, when there is an immerse number of different plastic parts shapes and materials used, there do not exist the exact theoretical and construction data for the correct form tempering. Usually, the experience of the designer preparing the given system is crucial, taking into consideration the other factors leading into a compromise with the other functional aspects of the form, such as the shape of the ejection system and its positioning, the shaping inlay, the adjustable parts, etc. [3]

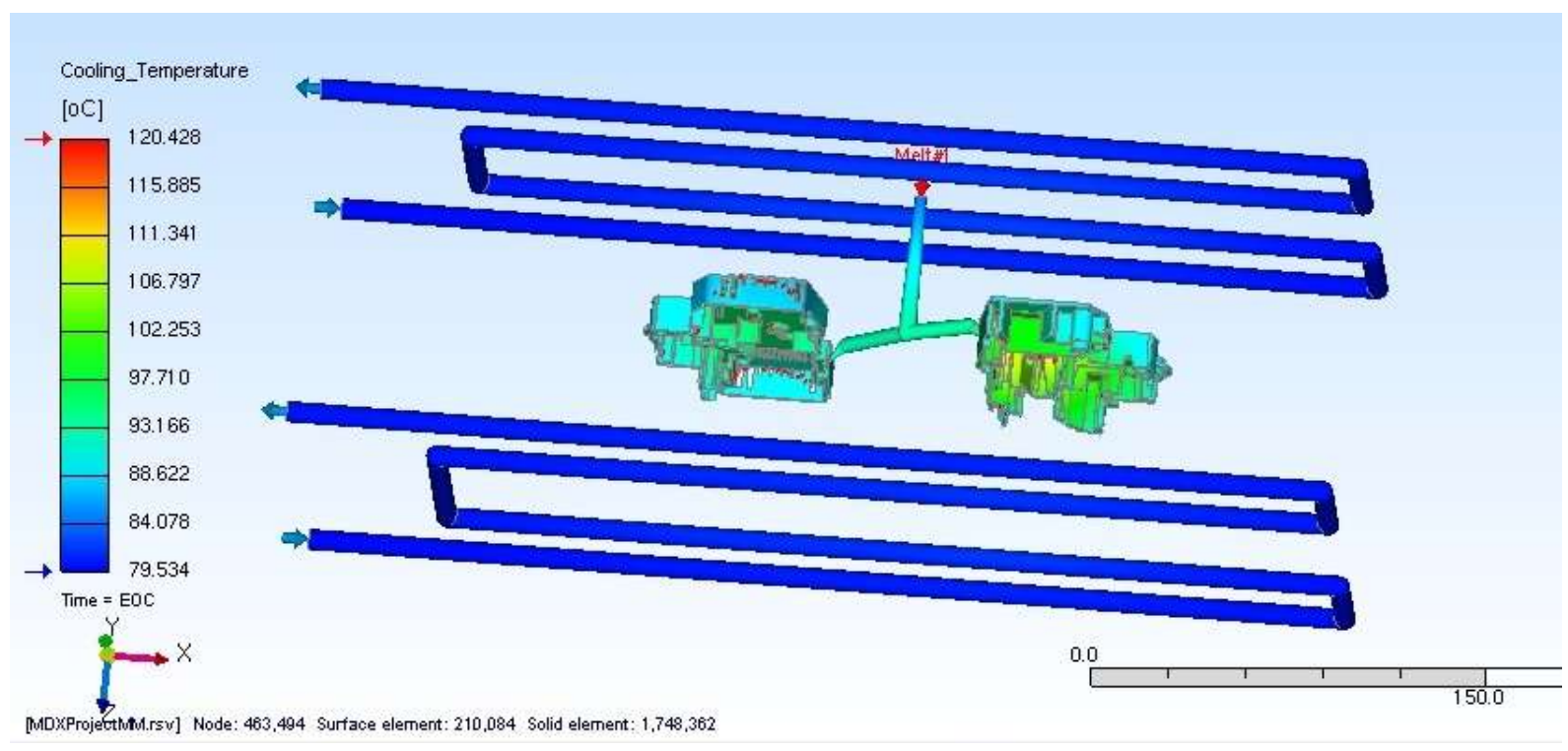

Fig. 10. Cooling temperature $120,429^{\circ} \mathrm{C}$.

The chosen cooling system should, in the first place, match the requirements of the equal cooling time of the melt along the shape intersection. This is today enabled by the Mold Flow or the Cadmould Cool simulation. This correctly designed cooling system ensures the minimal surface deformation of the mould part. 


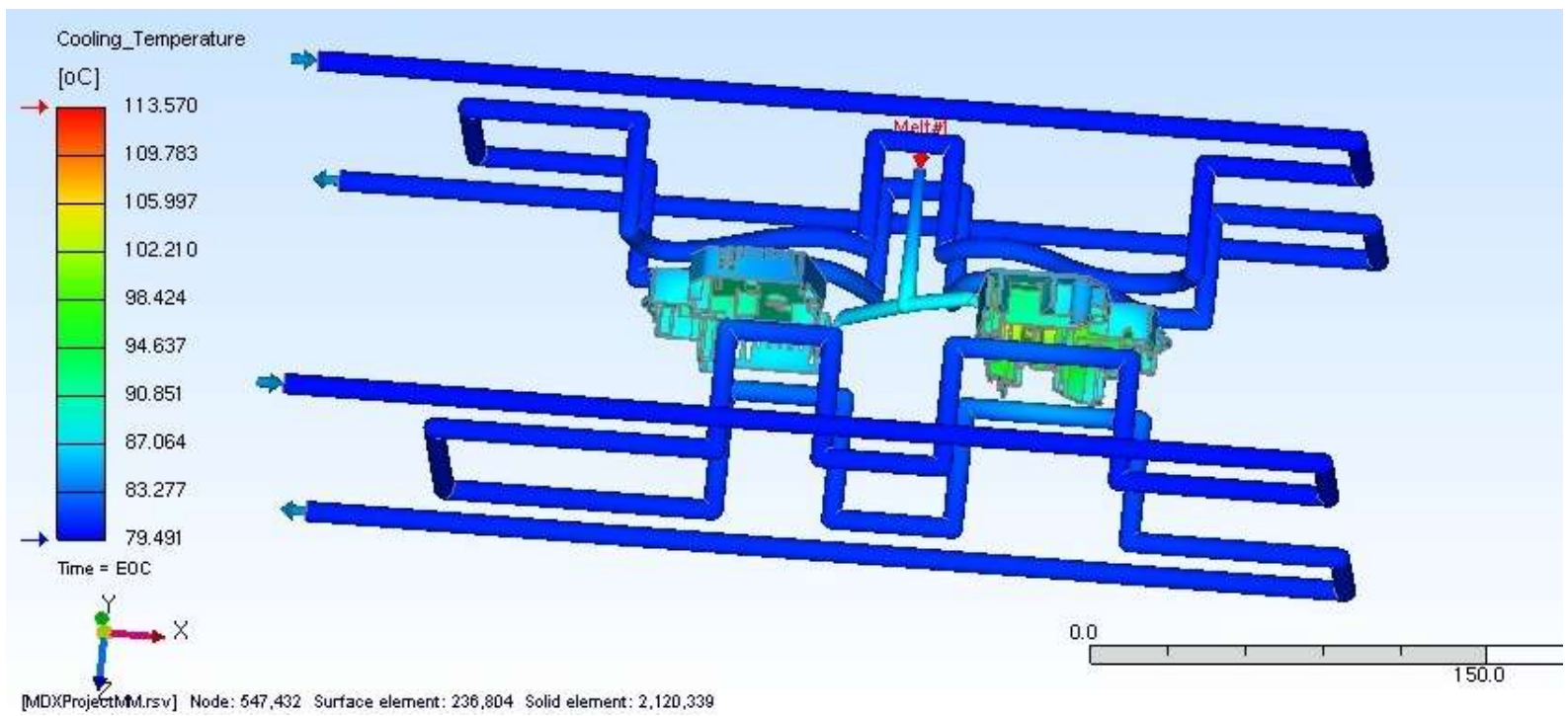

Fig. 11. Cooling temperature $113,570^{\circ} \mathrm{C}$.

New cooling system has reduced the surface temperature by $6,099^{\circ} \mathrm{C}$ less but deformation is still occurring.

The results of the comparisons deformations:

Table 3.Deformations results.

\begin{tabular}{|l|l|l|}
\hline Deformation Z-axis & Cavity 1 & Cavity 2 \\
\hline Original coolin gsystem & $0,654 \mathrm{~mm}$ & $0,710 \mathrm{~mm}$ \\
\hline New cooling system & $0.658 \mathrm{~mm}$ & $0,675 \mathrm{~mm}$ \\
\hline
\end{tabular}

\begin{tabular}{|l|l|l|}
\hline Deformations - Flatness & Cavity 1 & Cavity 2 \\
\hline Original cooling system & $0,55 \mathrm{~mm}$ & $0,60 \mathrm{~mm}$ \\
\hline New cooling system & $0.58 \mathrm{~mm}$ & $0,55 \mathrm{~mm}$ \\
\hline
\end{tabular}
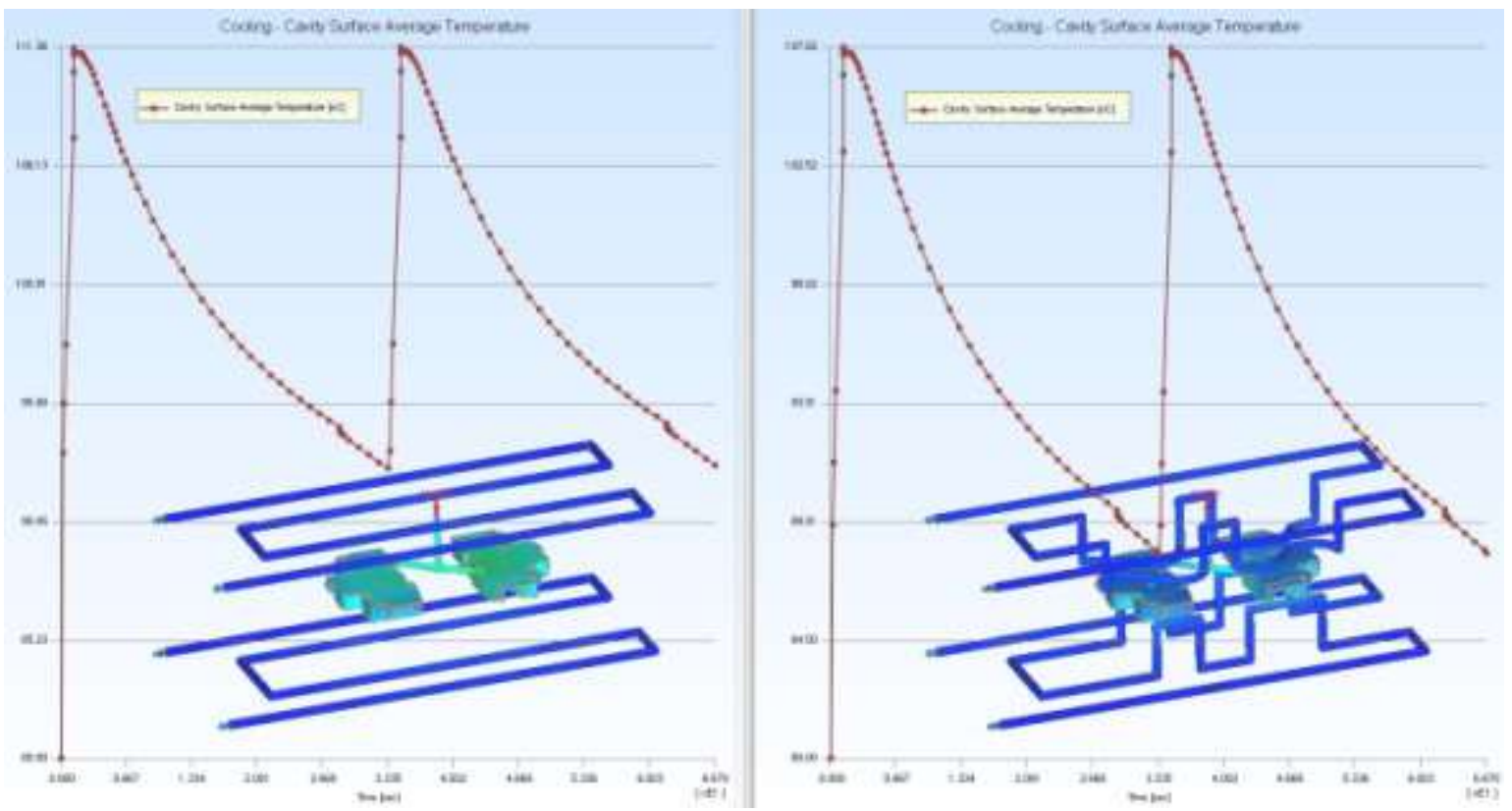

Fig. 12. Cooling - Cavity surface average temperature. 
Graph. 1. Graph od deformation results.

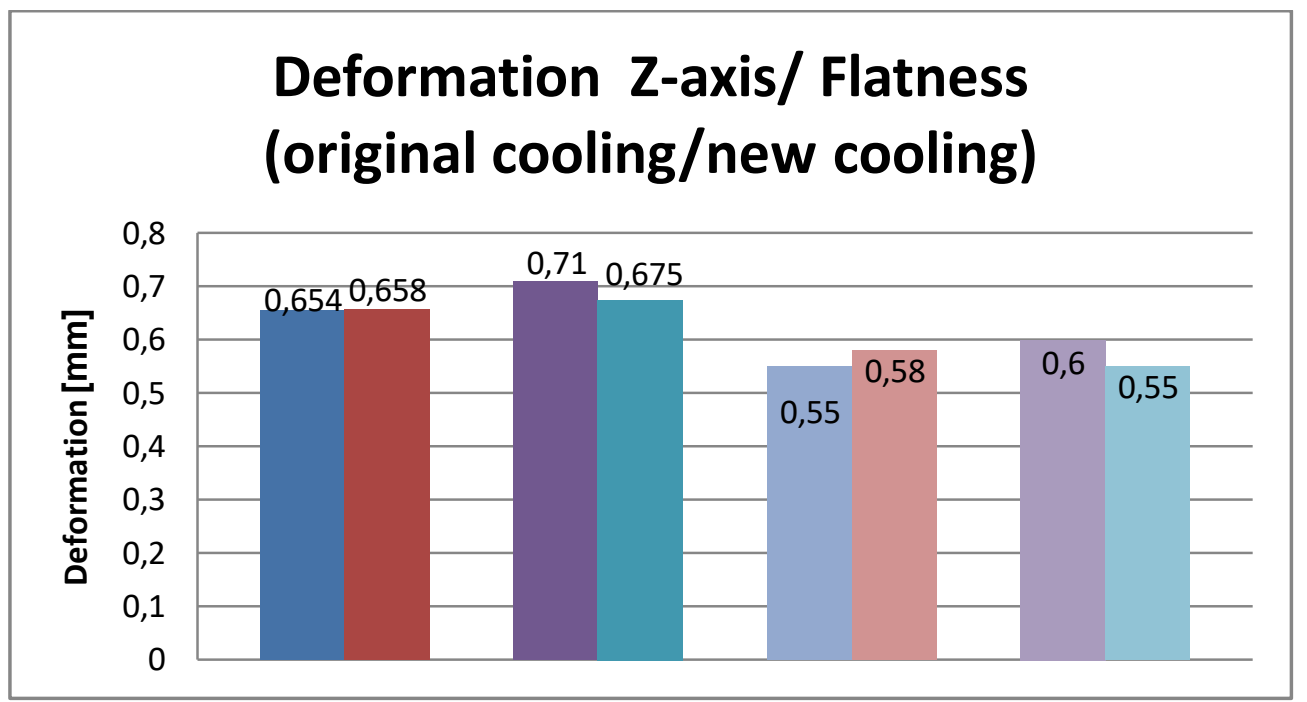

\section{Conclusion:}

Reducing the surface temperature of the part does not influence the deformation. The deformation could be reduced by changing the input parameters

The simulation process can, in many cases, ease the debugging and verification of the chosen construction, technology and the whole construction process. The cooling usually needs to be done in the best way possible, since every businessman wants the shortest production time possible. The better cooling the shorter cycle and the mould part can be delivered to the customer sooner. A change in the cooling, for example adding or changing the position of the cooling canal, causes changes in the deformations. The difference in temperatures during a balanced cooling at $5^{\circ} \mathrm{C}$ is within the tolerance range. During the simulation, the temperature of the form and of the material can be changed. If there is a problem with the injection, the simulation of the temperature change from $80^{\circ} \mathrm{C}$ to $90^{\circ} \mathrm{C}$ brings better results of the mould part behaviour. Many things are given with the mould part construction, which are in the end the initial phases of the process, where simulations are needed to remove defects and fasten the production.

\section{References:}

[1] BĚHÁLEK, L.: Plastové výrobky a jejich kvalita povrchu. In: Povrcháři, č.3, 2008, s. 4-5. ISSN 1802-9833.

[2] RAGAN, E. et al.: Vstrekovanie a spracovanie plastických hmôt, Prešov, FVT TU, 2008, ISBN 978-80-553-0102-0

[3] ŘEHULKA,Z.:Konstrukce výlisku z plastu a forem pro zpracovaní plastu. SEKURKON, organizačná a vzdělávací servis. 2001, 225s. ISBN:80-86604-18-7.

[4] S. HRIC, A. VAGASKÁ, S. RADCHENKO, F. MURGAŠ, M. MIČKO: Product quality improvement using simulation tools. P77-82; Research in Engineering and Management of Advanced Manufacturing Systems, 2014. ISBN-13:978-303835-377-5.

[5] SÁGA, Milan: Úvod do optimalizácie strojov a zariadení. Košice : TU-Sjf, 2006.ISBN 80-8073-656-1.

[6] Moldflow simulation - available on the internet [online: 2017-01-14].

$<$ https://knowledge.autodesk.com/support/moldflow-adviser/learn-

explore/caas/CloudHelp/cloudhelp/2014/ENU/MoldflowAdvisor/files/GUID-34915C5B-CBDC-4BB4-B976A8C940BB312A-htm.html>.

[7] PA66 - Polyamid 66; available on the internet [online: 2017-02-03]. <http://www.techplasty.sk/material/polyamid/pa66-polyamid-66>.

[8] Simulation temperature - available on the internet [online: 2017-03-12]. <https://www.slideshare.net/ijri/desing-ofmould-tool-cooling-channel-optimization-ofindustrial-helmet>. 